\title{
Improve the Ranking of Arab Universities in the World Universities Rankings
}

\author{
Marwan Abdul Hameed Ashour \\ Statistics Department, College of Administration and Economics, University of Baghdad, Baghdad, Iraq \\ Email address: \\ dr_marwan@uobaghdad.edu.iq

\section{To cite this article:} \\ Marwan Abdul Hameed Ashour. Improve the Ranking of Arab Universities in the World Universities Rankings. American Journal of \\ Environmental and Resource Economics. Vol. 4, No. 3, 2019, pp. 110-115. doi: 10.11648/j.ajere.20190403.14
}

Received: June 28, 2019; Accepted: July 23, 2019; Published: August 10, 2019

\begin{abstract}
The race to compete in the world rankings of universities is one of the most important priorities of scientific universities in recent times. The purpose of this paper is to reduce waste or losses of Arab scientific research outputs to a minimum and optimize the utilization of these outputs, which will positively affect the degree of ranking of Arab universities in the world ranking. The method used in this paper is as follows: statistical parametric theory, testing hypotheses and T-test. The most important conclusions reached through this paper are: The findings indicate that the weaknesses of the Arab universities are concentrated on the lack of scientific research published in the databases adopted in the world rankings of universities. The number of published world research and the number of quotations compared to the number of academics affect significantly and directly on the degree and rank of Arab universities when compared to world universities, The Arab journals should be re-habilitated to ensure that they are included in the Scopus database, and calculate all Arab researches publishing in the databases approved in the world ranking as described in the plan of improvement and approved by the Union of Arab Universities. And Establishing a partnership between International and local universities in the field of innovation. Furthermore, encouraging, holding an annual specialized forum for Arab with foreign academics.
\end{abstract}

Keywords: World Universities Ranking, Arab Universities Rankings, T-test, Improvement Plan

\section{Introduction}

The world ranking of universities is receiving increasing attention in recent times, as it is one of the most important methods of evaluating higher education, especially in the fields of scientific research, and has the largest role in the development of the policy of higher education, restructuring and setting goals. Hence, university ranking criteria seek to improve university competition and developed to measure the efficiency of outputs using quality standards. Despite of the different indicators in the world ranking, but there are effective indicators and important referred to the research and scientific productivity of faculty members in universities and have a prominent role in all of world ranking of universities. This paper, based on the criteria and indicators of ranking of QS, and the academic ranking of world universities ARWU, they are the most common among the world and Arab academics. Then, study the weaknesses of the indicators adopted in these ranking of Arab academics and evaluate the performance of Arab universities to improve their performance based on the indicators and standards adopted in the world ranking.

The problem of research is that there is no clear vision for the purpose of improving the ranking of Arab universities in the world ranking and adopting the criteria of those rankings. Therefore, the importance of research stems from the need to meet the requirements of the standards of world ranking of Arab universities and enter the competitive world environment, to develop the Arab university education environment through the adoption of the quantitative analysis method. The research hypothesis states that not counting all Arab research published in Arab journals is negatively impacting the degree and rank of Arab universities in the international classification of universities. There is a waste in the scientific and research output of Arab universities and the lack of optimal exploitation of the outputs of Arab scientific research. The research sample was included the world's most prestigious universities with high rankings in the world rankings.

The most important studies related to the research topic 
can be summarized as follows:

Moskovkin submitted a paper of Aggregate ranking of the world is leading universities [7]. Simon, presented a paper on the University Rankings and Social Science [8]. The researchers Liu and Cheng presented a paper on the academic ranking of world universities [14]. Researchers Jabjaimoh and elate, presented a paper on the optimization for Better World University Rank [1]. This study is characterized by conducting statistical tests and mathematical conclusions by comparing the results of the indicators of the best world and Arab universities. Then, identify the weaknesses and threats via the adoption of the best universities as a valid reference value for Arab universities and compare their results and propose an improvement plan for helping the administration to improve the Arab learning environment and institutions. The second part of this study includes measuring and comparing the scores of ten worlds and Arab universities, based on 10 indicators approved in the QS ranking. The most important conclusions and recommendations reached by the researcher in this study are the guide of methodology the procedures of Arab universities for improving their rankings in the world rankings of universities.

\section{The World Ranking of Universities}

Universities are rank descending according to a variety of criteria and indicators, as well as of the general statistics, and feedback of academics, students, and graduates of those institutions. There are many international recognized classifications in the classification of universities; it has based on a number of different criteria. A specific weight is assigned to each criterion or indicator. Then, it is classified in the light of the total score extracted from the criteria used. The most important international academic classifications of universities and the most common are as follows [1-6]:

\subsection{QS Ranking}

The classification of QS is one of the most important university rankings in the world. This classification started in 2004, and covers four strategic aspects related to higher education: scientific research, employability, educational efficiency, and global. The index published in the educational supplement of The Times, one of the British publications published jointly with the London-based educational consultancy "Quacquarelli Symonds" Which is an annual ranking of the best 800 universities in the world. The classification methodology deals with the best universities in the world "Top University", and based on five criteria are as follows [5, 6]:

1) The academic reputation depends on the opinion poll $40 \%$.

2) Employer's reputation is based on a $10 \%$.

3) Scientific Research "Quotation rate of research" 20\%.

4) Percentage of "academic" teachers to $20 \%$.

5) The proportion of foreign teachers and foreign students each, has $5 \%$.

The first and second criteria are calculated according to Global Survey by QS, in this year, there were 90,000 academics and 62,000 respondents last year. In terms of employment, the survey included 27,000 respondents, including various international companies such as ExxonMobil, Shell, Mercedes, Fox and others. The third criterion is calculated based on the quotations for publishing research within the scopes of the publisher's ambassador exclusively to the number of teachers. The fourth criterion is calculated according to the number of students and teachers already in the university. The fifth criterion depends on the number of teachers and foreign students already present at the university [5-8].

\subsection{Academic Ranking of World Universities}

This classification is the most widely used academic classes known as the Academic Ranking of World Universities (ARWU), issued by the Shanghai Jiao Tong University (Shanghai Jiao Tong University, a government research university in the People's Republic of China) since 2003. The academic classification of the universities of the world, which is adopted by UNESCO alone, is one of the distinguished projects through which the university seeks to analyze the academic level in universities according to the efficiency of the following criteria $[9,10]$ :

Table 1. Criteria for ranking the academic classification of international universities.

\begin{tabular}{llll}
\hline Standards & Weight & Symbol & Description \\
\hline Quality of education & $10 \%$ & Alumni & Number of university graduates who received the Nobel Prize and Fields \\
Quality of academics staff & $20 \%$ & Award & Number of university academics who received the Nobel Prize and Fields Medal \\
Research results & $20 \%$ & $\mathrm{HiCi}$ & The number of academics who have been highly citation for their research in various fields \\
& $20 \%$ & $\mathrm{N \& S} *$ & Number of published research in Nature or Science \\
& $20 \%$ & PUB & $\begin{array}{l}\text { The number of researches in Social Care Institute for Excellence (SCIE) and Social } \\
\text { Average behavior of academics }\end{array}$ \\
\hline
\end{tabular}

The criteria of the world rankings show that there is a significant and direct impact of scientific research. As well as, it has the largest weight and significant effects on the ranking and degree of universities in the global rankings of universities $[3,11]$.

\section{Results}

For the purpose of evaluating the performance of Arab universities and comparing them with the best world universities in accordance of the approach of total quality 
management (TQM) through the adoption of the universities world as a reference and value Benchmarks. The most important indicators approved in the QS index for 2015-2016 (Universities Rank, Number of lecturers, publish in Elsevier Journals, citation, Ratio of lecturers' to students, the Ratio of researches to lecturers', citation ratio to lecturers', the ratio of foreign students, the ratio of foreign lecturers', Classification of research type to university, University size depending on number of students). Twelve worlds, regional and Arab universities that have advanced positions in the Academic Ranking of world universities (ARWU) and QS index in 2016. The universities are: (Harvard University) which is the rank first, Cornell University that is the rank 13, and universities (Shanghai, Boston, Tehran, Istanbul, King Fahd, Cairo) the top 500 universities in that category, as well as, the Arab universities (Baghdad, Jordan, Alexandria, Ain Shams) among the top 800 universities in the QS index of the world universities in 2015. The universities were selected very carefully, including the top (50) universities in the world, and two regional universities that effecting of the Arab region, and the adoption of a number of Arab universities that are more common as a representative of Arab universities based on the reputation of these universities as shown in Table 2. The Scopes database has been adopted in the published research, citation, and data adopted in the QS index for the time period under consideration. As the Scopes database has been adopted in the published research, citation, and data adopted in the QS index for the time period under consideration. Whereas: the research represents the classification of scientific research, depending on the number of published research to lecturers, and the percentage of citation, self-citation, and three indicators are as follows: $\mathrm{VH}$ : Very High, Hi: High, MD: Medium, and LN: Limiter or None [15].

Table 2. Results indicators for some of international universities in QS for 2017.

\begin{tabular}{llllcc}
\hline Criteria University & Ranking & Faculty & Paper & $\begin{array}{l}\text { Paper per } \\
\text { faculty }\end{array}$ & $\begin{array}{l}\text { Citations per } \\
\text { Faculty }\end{array}$ \\
\hline Harvard & 3 & 4,184 & 67,461 & 16.1 & 117.2 \\
Ratio
\end{tabular}

The most important indicators (the ratio of citation to the number of academics, the ratio of published research to academic preparation, the percentage of students to academics, the total published research, and the total number of academics of the universities in question) can be represented graphically by the following graphs:

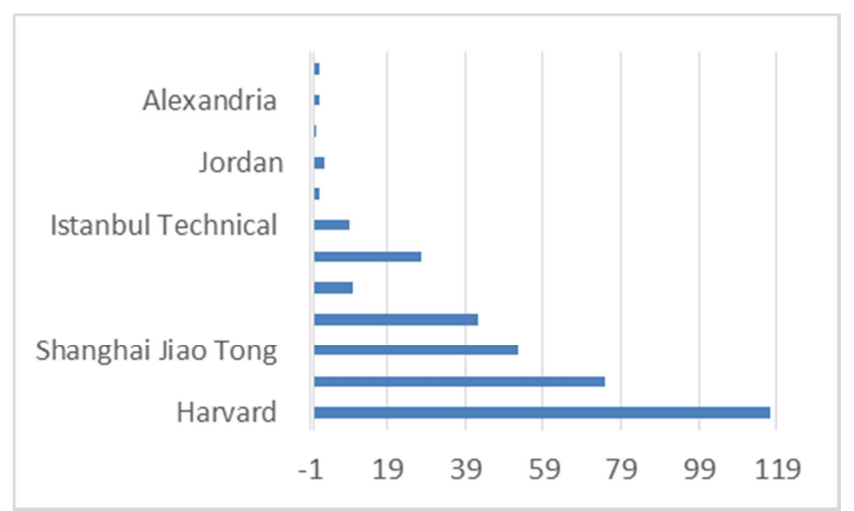

Figure 1. Citation ratio to academics of universities.

For the purpose of detecting which universities operate according to international standards, the t-test was used which is one of the most important was used statistical tests in the research and studies that has aimed at detecting the significance of statistical differences and comparing the mean of a sample with the assumed value of the population. It is calculated according to the following mathematical formula:

$$
\mathrm{t}=\frac{\mu \mu_{0}}{\mathrm{~S}_{\overline{\mathrm{x}}}}
$$

Where: $\mu$ : is the sample mean.

$\mu_{0}=$ The assumed average.

$\mathrm{S}_{\overline{\mathrm{x}}}=$ Standard error of sample.

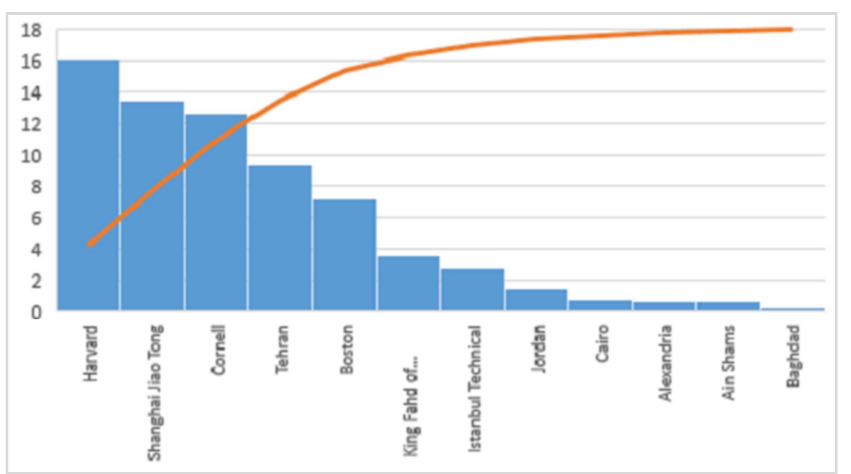

Figure 2. Represents ratio the published paper to the academics of the universities.

The statistical decision is taken if the differences are 
significant, the null hypothesis is rejected, and the alternative hypothesis is accepted. The statistical decision is taken if the differences are significant, the null hypothesis is rejected and the alternative hypothesis is accepted. The vice versa if the calculated ( $t$ value) located within the area of acceptance of the hypothesis $(-z \alpha, z \alpha)$. The null hypothesis is accepted which is expressed as $\mathrm{H}_{0}: \mu=\mu_{0}$ And the alternative hypothesis is rejected, which is expressed as $\mathrm{H}_{1}: \mu \neq \mu_{0}$ Which is called a two-part test and the test is one-sided lower (left) $\mathrm{H}_{1}: \mu<\mu_{0}$ or higher one-sided (right) $\mathrm{H}_{1}: \mu>\mu_{0}$. Where as, if $t$ calculate is outside the acceptance area of hypothesis, and within the rejection area of the hypothesis. The null hypothesis is rejected, and the acceptance of the alternative hypothesis. For the purpose of testing the existence of significant differences in the scientific research output of Arab universities compared to the worlddistinguished universities. Using equation (1), the t-test, the significance level 0.05 , and the freedom ( $\mathrm{d} . \mathrm{f}=11$ is 1.79 ), the assumed mean represents the rate of publication of research in the world's most prestigious universities, which are highly classified according to the QS ranking. By studying the results of the QS ranking of the top 300 World universities, the researcher concluded that the acceptable rank by which the classification of the research in a high level it is five. Therefore, the hypothesis of research or test as follows:

(The null Hypothesis: $H_{0}: \mu=5$, The alternative Hypothesis: $H_{1}: \mu<5$ )

\subsection{Analysis}

The results of the indicators presented in Table 2 and Figures 1 and 2 show that the highest percentage of research for the academic staff is 16 from Harvard University and the highest percentage of quotation to the academic is 117 for the same University. The value of Cornell University is higher than that of Shanghai University and significant. Hence, the rest of the university is arranged in Table 2. The proportion of research to the academic staff of Arab universities is less than $1 \%$, except for King Fahd University of 3.6, and the University of Jordan is 1.5 , and the percentage of the quotation to the academics is less than 2 in general a very small percentage compared with other international universities. The number of research is greater than the number of teaching staff of the world universities under consideration. The most of the Arab universities under study except King Fahd University and the University of Jordan, the number of research are less than the number of teachers, which indicates the existence of significant differences between the scientific research output compared to the numbers of teachers or academics in Arab universities. The number of research is greater than the number of teaching staff of the world universities under consideration. The most of the Arab universities under study except King Fahd University and the University of Jordan, the number of research are less than the number of academics, which indicates the existence of significant differences between the scientific research output compared to the numbers of teachers or academics in world universities. As shown by from the classification of the research field in the last column of table 2. All world and regional universities are under consideration and King Fahd University is ranked very high VH. While, all Arab universities are classified is rank limited notification LN. That is reflected on the degree and rank of Arab universities in the research column and their access to very weak degree in the sample of this research. The values of the test of the normal distribution of the purpose of diagnosing the rates of publication closest to the assumed rate according to the academic standards.

\subsection{Plan of Improvement}

The world rankings are based on scientific research at baseline and on research published within Scopus and Thomson Reuters. The previous results show that the results of the scientific researches of the Arab universities are weak. Based on the SWAT analysis where the weak points represent the lack of researches within the Scopus database compared to the number of academics', which led to the low degree and ranking of these universities in world ranks and research published within Scopus and Thomson Reuters. The strengths of point for locals and Arab publishing research are not within Scopus' base which is three times the number of academics (lecturers). Threats and opportunities are the rival of local and global universities in improving their rankings in the world rankings of universities. Arab universities encourage publishing in world journals within Scopus or Thomson Router; the results of this are not great. Arab universities encourage publishing in world journals within Scopus only, but the results are not great.

The researcher noted through their previous research and field experience in the field of world classifications of universities. Pointed out that there are Arab research has been published and prepared well and represent the strengths of untapped because most Arab magazines are not registered within the database Scopus. Moreover, it is found that the reason for the weakness of Arab scientific production is not only due to the lack of preparation and dissemination of Arabic research, but there are two main reasons:

1. The published Arabic researches are not calculated due they are not supported in the Scopus database index, which caused a waste of the results of the Arab scientific research.

2. The citation for Arab research is not calculated, which has affected the ranking of Arab universities in these rankings, as well as the low coefficient of the Arab academics, especially the humanities.

To address this situation and to improve the ranking of Arab universities in the world rankings of universities, and to ensure that they have advanced positions to be among the best 500 universities in the world should be use of the Arab scientific output as follow:

First: Re-qualify the Arab journals for entry into the Scopus database and this requires the following:

1. Technical criteria include the following criteria:

i. Peer evaluation.

ii. English Abstracts.

iii. Regular publication. 
iv. References in the Latin alphabet.

v. Ethics of publication and statement of the wrong practices.

2. Quantitative and qualitative measurements include the following:

a. Publishing policy includes:

i. Available English abstract.

ii. All references mentioned in the Roman alphabet.

iii. The Editorial policy is clear and understandable.

iv. Peer review level.

v. Diversity of editing.

vi. Diversity of authors.

b. Content quality includes:

i. Academic contribution.

ii. Clear abstracts.

iii. The publication agrees with the objectives of the journal.

c. Citations include:

i. Cite journal articles in Scopus.

ii. Cite from the editors at Scopus.

d. Regularity Includes: lack of delay in timeline of publication.

e. Accessibility includes:

i. Content available online.

ii. English only journal home page.

Second: To ensuring the calculation of the citation and (hIndex) for Arab research, Arab researchers should be committed to writing sources exclusively in English. This step probably ensures that there is a coefficient of $h$ for all Arab researchers and academics.

\section{Conclusions}

The main conclusions reached through this study can be summarized as follows:

1. The findings indicate that the weaknesses of the Arab universities are concentrated on the lack of scientific research published in the databases adopted in the world rankings of universities. The number of published world research and the number of quotations compared to the number of academics affect significantly and directly on the degree and rank of Arab universities when compared to world universities.

2. The lack of scientific research published in the databases adopted in the world ranking of Arab universities is due to the lack of optimal exploitation of the Arab scientific output and the waste of most of it. Where not all - Arab research is calculated through Scopus. Although, the fact that the numbers are large and representing a huge number of academics. It is within the average that makes Arab universities in the advanced positions in those rankings. In addition, the citation has not taken from Arab research even in the indexed journals within Scopes. This greatly affects the centers of the Arab universities because the percentage of the quotation has the largest weights in those rankings and the value of the coefficient (h-index) of the Arab academics.

3. To take advantage of the strengths of the Arab universities and optimize the exploitation of their scientific output and to address the weaknesses which will positively affect their ranking in the world academic ranking of universities.

4. The Arab journals should be re-habilitated to ensure that they are included in the Scopus database, and calculate all Arab researches publishing in the databases approved in the world ranking as described in the plan of improvement and approved by the Union of Arab Universities.

5. The adoption of Arabic journals of electronic systems in Submit, evaluate and publish research. In addition, adoption of standards and controls of the publication adopted by the publisher Elsevier and expanding the editorial board to include academics from different world universities.

6. The Arab journals for medical, engineering, and pure sciences were published in publisher Elsevier to obtain the impact factor from Thomson Reuters "ISI" as a first step due to publish in English, and then adopt the Arabic journals of other specialties published in Arabic.

7. Encouraging researchers to publish in journals that have a high impact factor, especially in the humanities.

8. Joint Scientific publishing adoption among academics in Arab and world universities with advanced positions in world ranking.

9. To raise the percentage of citation for researchers of Arab universities should be:

a. Adopting English language sources only for research written in Arabic or English in order to ensure the calculation of the coefficient of (h-index) for Arab academics, as this is reflected in the sequence of Arab universities and academics, especially in the humanitarian fields.

b. Encourage faculty members of Arab universities to cite and quote from research published in Scopus and Thomson Routers "ISI" belonging to researchers in Arab universities.

c. Polarization academics that have a coefficient $h$ higher than 5 at least in the Arab universities and East Asia, especially in the humanities.

10.Establishing a partnership between International and local universities in the field of innovation. Furthermore, encouraging, holding an annual specialized forum for Arab with foreign academics.

\section{References}

[1] P. Jabjaimoh, K. Samart, N. Jansakul, and N. Jibenja, 'Optimization for Better World University Rank', vol. 8, no. 1, pp. 18-20, 2019. 
[2] L. Leydesdorff, L. Bornmann, and J. Mingers, 'Statistical significance and effect sizes of differences among research universities at the level of nations and worldwide based on the leiden rankings', J. Assoc. Inf. Sci. Technol., vol. 70, no. 5, pp. 509-525, 2019.

[3] J. Pietrucha, 'Country-specific determinants of world university rankings', Scientometrics, vol. 114, no. 3, pp. 1129-1139, 2018.

[4] N. Kurniasih, C. Hasyim, A. Wulandari, M. I. Setiawan, and A. S. Ahmar, 'Comparative case studies on Indonesian higher education rankings', in Journal of Physics: Conference Series, 2018, vol. 954, no. 1, p. 12021.

[5] I. L. Sin, M. W. H. Leung, and J. L. Waters, 'Degrees of value: comparing the contextual complexities of UK transnational education in Malaysia and Hong Kong', Comp. A J. Comp. Int. Educ., vol. 49, no. 1, pp. 132-148, 2019.

[6] M. Farooq, S. Muhammad, V. Raju, K. R. Kalimuthu, A. Qadir, and others, 'Measuring and comparing the desired and actual service quality of Pakistan international airline', J. Soc. Sci. Res., vol. 5, no. 2, pp. 484-490, 2019.

[7] V. M. Moskovkin, 'Aggregate ranking of the world â€TM s leading universities', vol. 12, no. 1, pp. 1-10, 2015.

[8] M. Huang, 'A Comparison of Three Major Academic
Rankings for World Universities : From a Research Evaluation Perspective', vol. 1, no. June, pp. 1-25, 2011.

[9] C. Kao and H. Hung, 'Efficiency analysis of university departments: An empirical study', vol. 36, pp. 653-664, 2008.

[10] I. Measurement, 'Effectiveness of Schools' Management and Its Measurement - a Review of Concepts', vol. 6, pp. 105$112,2018$.

[11] D. Visbal-cadavid and F. Guijarro, 'Assessing the Efficiency of Public Universities through DEA. A Case Study', pp. 1-19, 2017.

[12] S. R. Agha, I. Kuhail, N. Abdelnabi, M. Salem, and A. Ghanim, 'Assessment of academic departments efficiency using data envelopment analysis', vol. 4, no. 2, pp. 301-325, 2013.

[13] A. De Calidad, 'Comparative study of international academic rankings', 2007.

[14] N. C. A. I. Liu and Y. Cheng, 'The Academic Ranking of World Universities', vol. 30, no. 2, 2005.

[15] P. Acosta-Vargas, T. Acosta, and S. Luján-Mora, 'Challenges to assess accessibility in higher education websites: A comparative study of Latin America universities', IEEE Access, vol. 6, pp. 36500-36508, 2018. 